\title{
The Scaling Up Nutrition (SUN) Movement and conflicts of interest in global nutrition governance
}

By Ann Louise Lie and Sabrina Ionata Granheim

This is a summary of an article published in the Journal of the Norwegian Medical Association

(Tidsskrift for Den norske legeforening) on 23 November 2017. The full article is titled

"Multistakeholder partnerships in global nutrition governance: protecting public interest?", and is available online, free of charge, at http://tidsskriftet.no/en/2017/10/global-helse/multistakeholderpartnerships-global-nutrition-governance-protecting-public. This summary is published in World Nutrition with the authorization of Tidsskriftet. 
Multi-stakeholder partnerships involving governments, international organisations, civil society and private sector actors have become key instruments in food and nutrition governance and for implementing the Sustainable Development Goals. While partnerships may provide effective solutions to policy problems by drawing on skills and resources from different stakeholders, there should be a limit to the level of involvement of actors whose interests conflict, or may seem to conflict, with public agencies' agendas. Businesses whose profit depends on marketing and sales of unhealthy food and beverages may for example reframe malnutrition problems in their own interests (e.g. as the result of individual behaviour only), influence public health agendas and priorities, fund research seeming to support their views, and interfere with legislative processes to derail industry regulation. Such undue influence could perhaps be overcome through more effective prevention and management of conflicts of interest. In order to explore this topic, we discuss the respective roles and activities of the World Health Organization (WHO) and the Scaling Up Nutrition Movement (SUN Movement) in providing normative guidance for governments on how to protect nutrition policy from undue influence.

Through the endorsement of the "Comprehensive implementation plan on maternal, infant and young child nutrition" by Member States at the World Health Assembly in 2012, WHO was mandated to 'form alliances and partnerships to expand nutrition actions with the establishment of adequate mechanisms to safeguard against potential conflicts of interest' (1). Member States also mandated WHO to 'develop risk assessment, disclosure and management tools to safeguard against possible conflict of interest in policy development and implementation of nutrition programmes consistent with WHO's overall policy and practice' (1). Since then, WHO has adopted a policy to guide its engagement with non-state actors (2) and is currently working to develop guidance for countries on prevention and management of conflicts of interest in the nutrition policy process. The guidance will be presented at the World Health Assembly in 2018.

In contrast to WHO, the SUN Movement is not a specialised UN agency whose role is to perform normative and analytical functions mandated by Member States. Rather, the SUN Movement has the self-appointed role of coordinating nutrition actors at the global level, advocating for and mobilising funding for nutrition, and supporting country-level action in the area of malnutrition. One of its key aims is to establish multi-stakeholder partnerships for nutrition within its member countries. The close involvement of food corporations in these partnerships raises concerns about whose interests are promoted through the SUN Movement. Through its Business Network, 268 companies have committed to supporting countries' efforts to scale up nutrition action (3).

In 2013, the SUN Movement began developing guidelines for its member countries on how to address such conflicts. The guidance, "A Reference Note and a Toolkit for Preventing and Managing Conflicts of Interest," was financed by the Bill and Melinda Gates Foundation, and developed by a private consultancy firm $(4,5)$. This guidance has been widely disseminated within the SUN Movement's 59 member countries and is currently being used by its members, including the Business Network, to guide governments' efforts to address conflicts of interest when developing their nutrition policies and programmes. We have concerns regarding its intentions, its content, and the possibility of its interference with WHO's norm-setting role. Our main concerns are:

1. The purpose of the SUN Movement's guidance does not seem to be to protect the integrity, independence and public trust in individuals and institutions serving public interests, but rather to ensure effective functioning of the partnership itself and to promote inclusion of new partners, particularly from the private sector.

2. The definition of "conflicts of interest" used conflates conflicts of interest with concepts such as 'diverging interests' between different actors, and by suggesting that any type of 
collaboration can lead to conflicts of interest, downplays concerns about conflicts arising between primary and secondary interests (for example public health versus profits).

3. Many of the principles of engagement upon which the guidelines are based conflict with an effective conflict of interest policy, such as its principles 'to be inclusive' and 'to be willing to negotiate'. It does not mention that in order to avoid undue influence on public policymaking, exclusion of actors with perceived or actual conflicts of interest is sometimes necessary. To the contrary, the SUN guidance encourages actors to 'limit the scope and duration of any exclusionary decision' $(5$, p. 21$)$ on the grounds that it contradicts other irrelevant and artificially added principles of the partnership. As a consequence, having committed to being members of the SUN Movement, governments' abilities to withstand pressure and attempts at industry interference may be undermined.

4. The SUN Movement's guidance principle 'to be predictable and mutually accountable' suggests that governmental and non-governmental actors alike have equal responsibilities. While every partner has a role in a partnership, the roles and responsibilities of the various actors are not at the same level. Governments are primarily accountable to citizens, not to other members of such partnerships.

5. The SUN Movement's guidance is weak in the measures it proposes to prevent and manage conflicts of interest. It recommends protection of confidentiality and privacy in the disclosure process, which contradicts the principle of transparency-critical for controlling conflict of interest.

6. Rather than encouraging the development of an independent process for managing conflict of interest, the guidance recommends that 'Mechanisms for managing conflicts of interest should include all stakeholders - including those with a perceived or potential conflict of interest' (5, p. 20).

These issues indicate that the SUN Movement's Reference Note and Toolkit do not provide an appropriate or sufficient response for protecting food and nutrition policy-making from undue commercial influence. Rather than providing clear advice to governments on how to address conflicts of interest while engaging in partnerships, the SUN Movement's guidance seems to encourage inclusiveness above all else, and conveys an erroneous understanding of what 'conflicts of interest' means, undermining the authority of member-state mandated organisations such as WHO, and of governments themselves. Additionally, the overlap with WHO's work on country guidance on conflicts of interest may lead to weaker measures to protect nutrition than other sectors, and an additional burden on already overstretched government staff to deal with the differing approaches.

While multi-stakeholder partnerships have the potential to draw on resources and skills from different actors in order to improve effectiveness of nutrition interventions, they create real risks and challenges to food and nutrition policy-making that need to be acknowledged and appropriately addressed. Organisations like SUN which themselves may have conflict of interest issues in how they are constituted should not provide normative guidance to governments on how to protect public health from undue influence.

\section{References cited in the summary}

1. World Health Organization. Comprehensive implementation plan on maternal, infant and young child nutrition. World Health Assembly Resolution WHA65.6. 2012. http://www.who.int/nutrition/publications/CIP document/en/(12.7.2017).

2. World Health Organization. Framework of engagement with non-state actors. World Health Assembly Resolution WHA69.10. 2016. http://www.who.int/about/collaborations/non-state-actors/A69_R10-FENSA-en.pdf?ua=1 (12.7.2017). 
3. SUN Business Network. SUN Business Network Company Commitments. 2017. http://sunbusinessnetwork.org/wpcontent/uploads/sites/2/2015/01/SUN-Business-Network-Company-Commitments-09-Jan-2017.pdf (14.7.2017).

4. SUN Movement. Preventing and Managing Conflicts of Interests: Background. 2015. http://scalingupnutrition.org/sharelearn/multistakeholder-engagement/preventing-and-managing-conflicts-of-interest/ (20.7.2017).

5. Global Social Observatory. Engaging in the SUN Movement: Preventing and Managing Conflicts of Interests. Reference Note and Toolkit. 2015. http://docs.scalingupnutrition.org/wp-content/uploads/2014/05/Reference-Note-and-ToolkitEnglish.pdf (14.7.2017). 